\title{
Climate Change and Mitigation
}

\author{
Kerstin Nibleus, Rickard Lundin
}

Published online: 7 July 2010

\begin{abstract}
Planet Earth has experienced repeated changes of its climate throughout time. Periods warmer than today as well as much colder, during glacial episodes, have alternated. In our time, rapid population growth with increased demand for natural resources and energy, has made society increasingly vulnerable to environmental changes, both natural and those caused by man; human activity is clearly affecting the radiation balance of the Earth. In the session "Climate Change and Mitigation" the speakers offered four different views on coal and $\mathrm{CO}_{2}$ : the basis for life, but also a major hazard with impact on Earth's climate. A common denominator in the presentations was that more than ever science and technology is required. We need not only understand the mechanisms for climate change and climate variability, we also need to identify means to remedy the anthropogenic influence on Earth's climate.
\end{abstract}

Keywords Climate change - Carbon sequestration . Methanol economy $\cdot$ Artificial climate control

Planet Earth has experienced repeated changes of its climate throughout time. Periods warmer than today as well as much colder, during glacial episodes, have alternated over the course of time. In our time rapid population growth, with the consequent increased demand for natural resources and energy, has made society increasingly vulnerable to environmental change, both natural and anthropogenic; human activity is clearly affecting the radiation balance of the Earth.

The Intergovernmental Panel on Climate Change (IPCC) Working Group 1 (The Physical Science Basis) presented a broad, systematic summary of the scientific literature on climate change and concluded that the anthropogenic emission of greenhouse gases has led to an increase in the surface temperature of the Earth. As noted by IPCC, quantification of the influences on the global climate is complex and many regional effects remain uncertain.

\section{EARTH'S CLIMATE AND CLIMATE CHANGE}

The Earth's temperature is kept in balance, and allows life as we know it, thanks to the presence of so-called greenhouse gases in the atmosphere. These are dominated by water vapour and carbon dioxide $\left(\mathrm{CO}_{2}\right)$ and include a number of other gases which contribute somewhat less to the total. However, the concentrations of several greenhouse gases are significantly influenced by human activities. In addition to $\mathrm{CO}_{2}$, these gases include $\mathrm{CH}_{4}, \mathrm{~N}_{2} \mathrm{O}$ and $\mathrm{CFCs}$. The effect on the climate is both direct and indirect through the associated increase in atmospheric water vapour with temperature.

The concentration of $\mathrm{CO}_{2}$ in the atmosphere during the past 2000 years has been about $280 \mathrm{ppm}$. During the past 150 years, $\mathrm{CO}_{2}$ and $\mathrm{CH}_{4}$ have increased and there are strong indications that their concentrations are the highest for at least the last 800,000 years. The total increase of $\mathrm{CO}_{2}$, for example, amounted to $23 \%$ between 1958 (when accurate measurements began) and 2009, i.e. a rise from 315 to $386 \mathrm{ppm}$. Isotope records show that the $\mathrm{CO}_{2}$ increase is primarily related to anthropogenic emissions, in contrast to earlier periods in Earth's history. Most of this increase is due to the burning of fossil fuels, but about $20 \%$ is due to land-use change, including deforestation and biomass burning.

During the past century, there has also been an increase in the concentrations of aerosol particles in the atmosphere, 
due to emissions from burning of fossil fuels and biomass. Whereas some of these particles (soot) contribute to global warming, others, e.g. sulphate and organics, reflect sunlight back into space and tend to cool the planet. The present understanding is that the net effect of all particles is a cooling and that this has masked a significant part of the general warming trend of the past century.

Whilst the effect of greenhouse gases is well established, the effect of aerosols (mainly providing a compensating cooling) is less understood. This is one reason why models provide a broad range of response. Other reasons for differences in the response of models are internal processes in the climate system (including the role of clouds), which are essentially unpredictable beyond a period of less than a year. The relation between climate change and changes in greenhouse gases and aerosols is complex, and there is no simple direct (spatial or temporal) relationship.

It has been shown that an increased content of $\mathrm{CO}_{2}$ in the atmosphere can potentially lead to more rapid growth of vegetation, although the effect is difficult to predict in view of other limiting environmental factors, such as availability of nutrients, water supply, and suboptimal temperature regimes. In addition, it has also been shown that increased atmospheric $\mathrm{CO}_{2}$ concentration is causing acidification of the oceans, with potentially severe effects on marine ecosystems.

Owing to the current slow rate of implementation of alternatives to the burning of fossil fuels and biomass, and the world's increasing energy requirements, $\mathrm{CO}_{2}$ levels are expected to continue to increase significantly during this century (during the last 5 years, the increase has been $\mathrm{c}$. $10 \mathrm{ppm}$ ). Limitations in the hydrocarbon resource base will reduce the future increase in the anthropogenic emissions. Nevertheless, the long-term risks are related to the effect of $\mathrm{CO}_{2}$ accumulation as a result of a steady buildup and a long residence time in the atmosphere. Towards the middle of this century, a concentration of between 450 and $500 \mathrm{ppm}$ can probably not be avoided. Without remediation efforts, high levels of atmospheric $\mathrm{CO}_{2}$ may exist for millennia. Increases in the concentrations of other greenhouse gases such as $\mathrm{CH}_{4}$ and $\mathrm{N}_{2} \mathrm{O}$ are less clear, and these are not directly related to the use of fossil fuels.

The presentations at the Energy Committee's seminar "Energy 2050" "Climate Change and Mitigation" session offered four different viewpoints on coal and $\mathrm{CO}_{2}$ : i.e. as the basis for life, but also as a major hazard with impact on the Earth's climate. A common denominator in the presentations at this session was that more science and technology initiatives will be required, in order to better understand the underlying mechanisms for climate variability. More science and technology is essential to identify means to remedy anthropogenic influences on the Earth's climate. In what follows a summary of the presentations is presented. Including:

- Beyond fossil fuels and the recycling of coal (methanol economy) (Prof. Olah);

- New $\mathrm{CO}_{2}$ capture and storage technologies (Prof. Lackner);

- The option of drastic climate engineering methods to control the Earth's climate (Prof. Cox);

- Atmospheric $\mathrm{CO}_{2}$ and the status of climate change research (Prof. Bengtsson).

\section{BEYOND FOSSIL FUELS}

Professor George Olah sees the Sun as man's most important source of energy. No energy shortage is foreseeable, but we need better methods to capture, store and use energy. Photosynthesis, using the Sun's energy with chlorophyll in plants as a catalyst to recycle $\mathrm{CO}_{2}$ and water into new plant life, is an effective but very slow way to capture and store energy. On geological time scales the biosphere has managed to build up fuel deposits in the form of coal, oil, and gas, a "gift" enabling humans to develop our advanced, but very energy demanding technological societies. However, the ever-increasing demand on energy by a growing world population will eventually lead to a change, from fossil coalbased fuel to other energy sources. One may argue that the photosynthesis is too slow to cope with the demand on both food and energy. Nonetheless, combustion of coal and carbohydrates will probably remain the most efficient way to produce energy also in future societies.

In today's debate on climate change, $\mathrm{CO}_{2}$ and coal represent a "problem", to the extent of their being regarded as poisonous. However, $\mathrm{CO}_{2}$ is also the basis for photosynthesis and carbon is the building block for biological life. Carbon is apparently associated with two conflicting aspects, the environmental effect in excessive concentrations versus the essential element for terrestrial life, i.e. the Carbon Conundrum. Whilst the limited fossil fuel resources are increasingly depleted, we will have to deal with the conflicting aspects of carbon. Modern technology, with chemical recycling of carbon, offers a way to maintain a "carbon society" beyond fossil fuels.

In contrast to photosynthesis, chemical recycling of $\mathrm{CO}_{2}$ from natural and industrial sources as well as varied human activities or even from the air itself to methanol or dimethyl ether (DME) and their varied products can be achieved via capture, and subsequent reductive hydrogenative conversion. Carbon recycling represents a significant aspect of the Methanol Economy. Any available energy source (alternative energies such as solar, wind, geothermal and atomic energy) can be used for the production of needed 


\section{Technological Carbon Cycle}

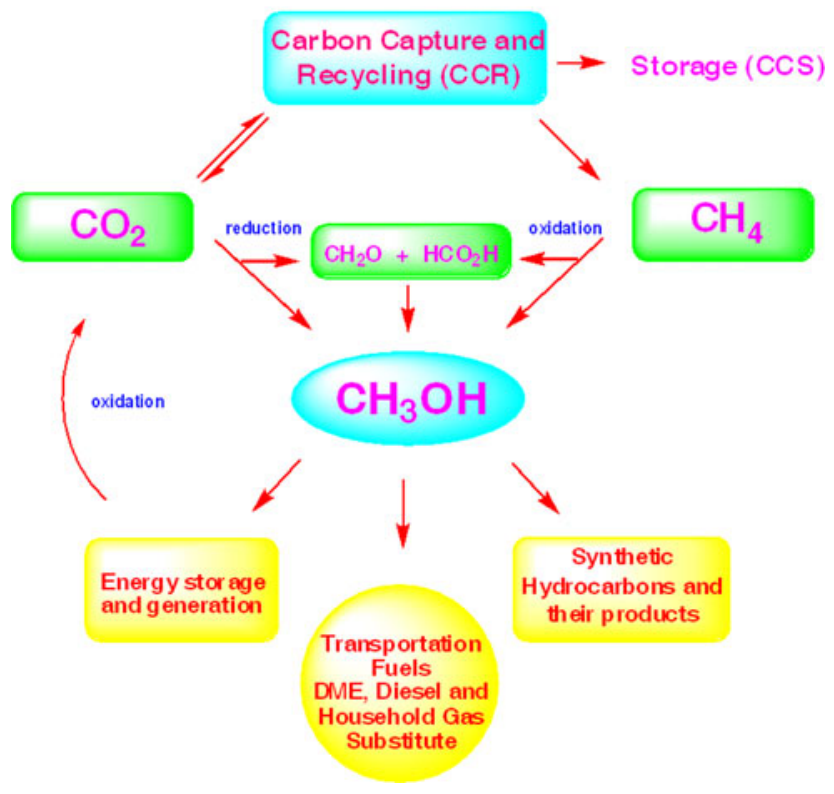

Fig. 1 The technological Carbon Cycle (Courtesy of G. Olah, 2010)

hydrogen and chemical conversion of $\mathrm{CO}_{2}$. Improved new methods for the efficient reductive conversion of $\mathrm{CO}_{2}$ to methanol and/or DME that have been developed include bi-reforming with methane and ways of catalytic or electrochemical conversions. Together with the derived DME, methanol represents excellent transportation fuels for internal combustion engines (ICE) and fuel cells as well as convenient starting materials for synthetic hydrocarbons and their varied products.

Recycling of carbon, chemically transformed from a detrimental greenhouse gas, causing global warming, into a valuable, renewable and inexhaustible carbon source of the future allowing environmentally neutral use of carbon fuels and derived hydrocarbon products.

The diagram in Fig. 1 illustrates the technological carbon cycle. Notice that the core of the diagram (Carbon Capture and Reuse) maintains a reuse of carbon, avoiding the Carbon Capture and Sequestration (CCS). In CCS carbon is removed and stored, regarded as a "problem", whilst CCR considers carbon as a future resource.

The technological carbon cycle to produce methanol is not just a hypothesis to be tested, but is in fact already in use at various sites. Iceland was the first country to derive methanol from $\mathrm{CO}_{2}$ from the Earth's interior. Several coalplants in China have also installed test facilities and plan for a massive production of methanol at their 100 megaton coal power plants.

Methanol, produced via the technological carbon cycle, is therefore not only an important tool for mitigation, i.e. to take care of the additional $\mathrm{CO}_{2}$ delivered by man to the Earth's atmosphere. Producing methanol is also an effective way to store energy. Methanol and DME may become the fuel for combustion engine transportation, replacing fossil fuels with inexhaustible universal availability. The methanol economy may also substitute household and heating gas. Methanol is also a valuable source material for olefins (ethylene, propylene) and derived synthetic hydrocarbons and their products. Methanol has also proved to be a feasible alternative to produce electricity by electrochemical means (fuel cells). Finally, the technological carbon cycle can form the basis for synthetic protein production.

\section{MANAGING THE BUILDUP OF $\mathrm{CO}_{2}$ FROM FOSSIL FUEL CONSUMPTION}

Professor Klaus Lackner says that the world needs affordable, plentiful and clean energy for all. Fossil carbon is not running out - but the atmospheric $\mathrm{CO}_{2}$ level must be stabilized. That means we must stabilize $\mathrm{CO}_{2}$ concentration but not necessarily $\mathrm{CO}_{2}$ emissions. Amongst the options for carbon capture, capturing $\mathrm{CO}_{2}$ from the air is particularly attractive, as it could be implemented without interfering with existing infrastructures. Air capture could deal with any emission source, also far away from the source and thereby provide a capture method of last resort. For large, concentrated sources of $\mathrm{CO}_{2}$ capture at the source would usually be preferable and more economic.

However, air capture could address emissions from small and distributed sources, like airplanes and cars. It can also be used to reduce the $\mathrm{CO}_{2}$ concentrations in the atmosphere. Our recent progress has made it economically interesting to consider large-scale, widespread application of air capture.

Once collected $\mathrm{CO}_{2}$ must be either recycled into a new carbon-based fuel or disposed of safely and permanently. Fuel recycling requires low cost electric power from nonfossil sources to provide the energy for reducing carbon and hydrogen. Today, such electric power is rarely available. Until such sources are developed $\mathrm{CO}_{2}$ can be stored either through underground injection into geological formations or the production of solid mineral carbonates from mineral rock and $\mathrm{CO}_{2}$.

Figure 2 shows a system for net saving of $8.5 \mathrm{~g} \mathrm{CO}_{2}$ per second.

However, for coal-based electricity production the power plant efficiency will be reduced by $25 \%$.

In order to achieve closure in the anthropogenic carbon cycle with carbon capture and storage technologies, it is necessary to provide a convincing methodology for a quantitative accounting of the carbon stored. This is easier in the case of mineral carbonation, but here we suggest an approach that could make quantitative inventories possible in either case. Thus, the technologies for a carbon-neutral 
Fig. 2 One ton per day unit

\section{Air Capture Material and Energy Flow}

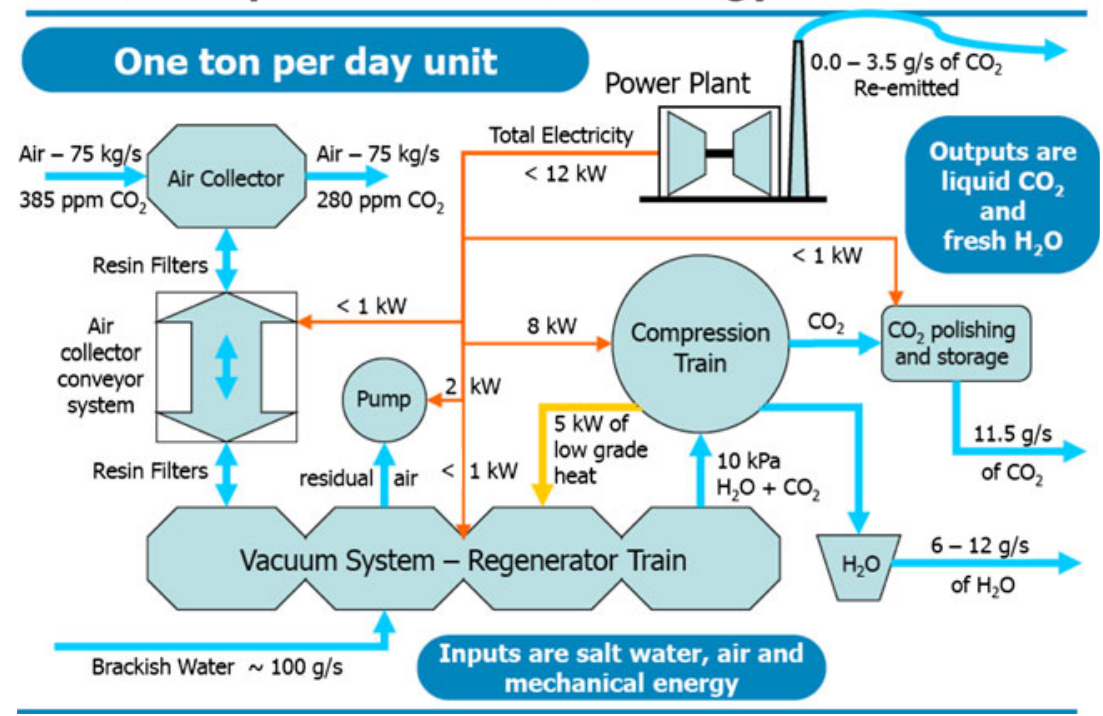

fossil fuel-based energy system exist, and it is likely that these technologies will play an important role in satisfying the energy demand of the twenty-first century.

The world must stop the accumulation of $\mathrm{CO}_{2}$ in the atmosphere. At the same time, we must improve energy services for a growing world population that strives for a high standard of living. Carbon capture and storage technologies can avoid the stark choice between economic growth and a healthy environment. They allow continued access to abundant fossil fuels whilst eliminating the threat of climate change. The only other choice would be to eliminate all fossil fuels. Because of the worldwide rapid growth in energy demand, this could precipitate a major energy crisis.

\section{GEOENGINEERING THE CLIMATE: THE FINDINGS OF THE ROYAL SOCIETY STUDY}

Professor Peter Cox shows that in recent decades our scientific understanding of the climate system has improved dramatically. There is now widespread belief that a global warming of greater than $2^{\circ} \mathrm{C}$ above pre-industrial levels would be dangerous and should therefore be avoided. However, despite growing concerns over climate change, global $\mathrm{CO}_{2}$ emissions have continued to climb. This has led some to suggest more radical "geoengineering" alternatives to conventional mitigation via reductions in $\mathrm{CO}_{2}$ emissions.

Geoengineering is deliberate intervention in the climate system to counteract man-made global warming. There are two main classes of geoengineering;

1. Direct $\mathrm{CO}_{2}$ removal; and

2. Solar radiation management, which aims to cool the planet by reflecting more sunlight out to space.
A group has been formed at the United Kingdom's Royal Society with the particular aim to remove the confusion about what geoengineering implies. A Royal Society policy study was carried out between October 2008 and September 2009, reviewing peer review science literature from 1975 and onwards. The scope of the study was to include all methods, which involve deliberate large-scale interventions of the Earth's natural climate system, but excluding:

(a) Low carbon energy and methods for reducing emissions of greenhouse gasses.

(b) Carbon Capture and Storage (CCS).

(c) Conventional afforestation and avoided deforestation schemes.

An evaluation of the following issues was made:

Effectiveness:

What is the magnitude of the possible effect on global climate?

Timeliness:

What is the readiness of the techniques?

With what speed would the intended effect occur?

Safety:

How likely are unintended environmental impacts (including regional)?

Affordability:

What is the likely cost of deployment and operation, for a given desired effect on global climate?

Information on costs is extremely tentative and incomplete-only order of magnitude estimates are possible. 
Fig. 3 Carbon dioxide removals. Effectiveness versus affordability
Fig. 4 Solar radiation management. Effectiveness versus affordability
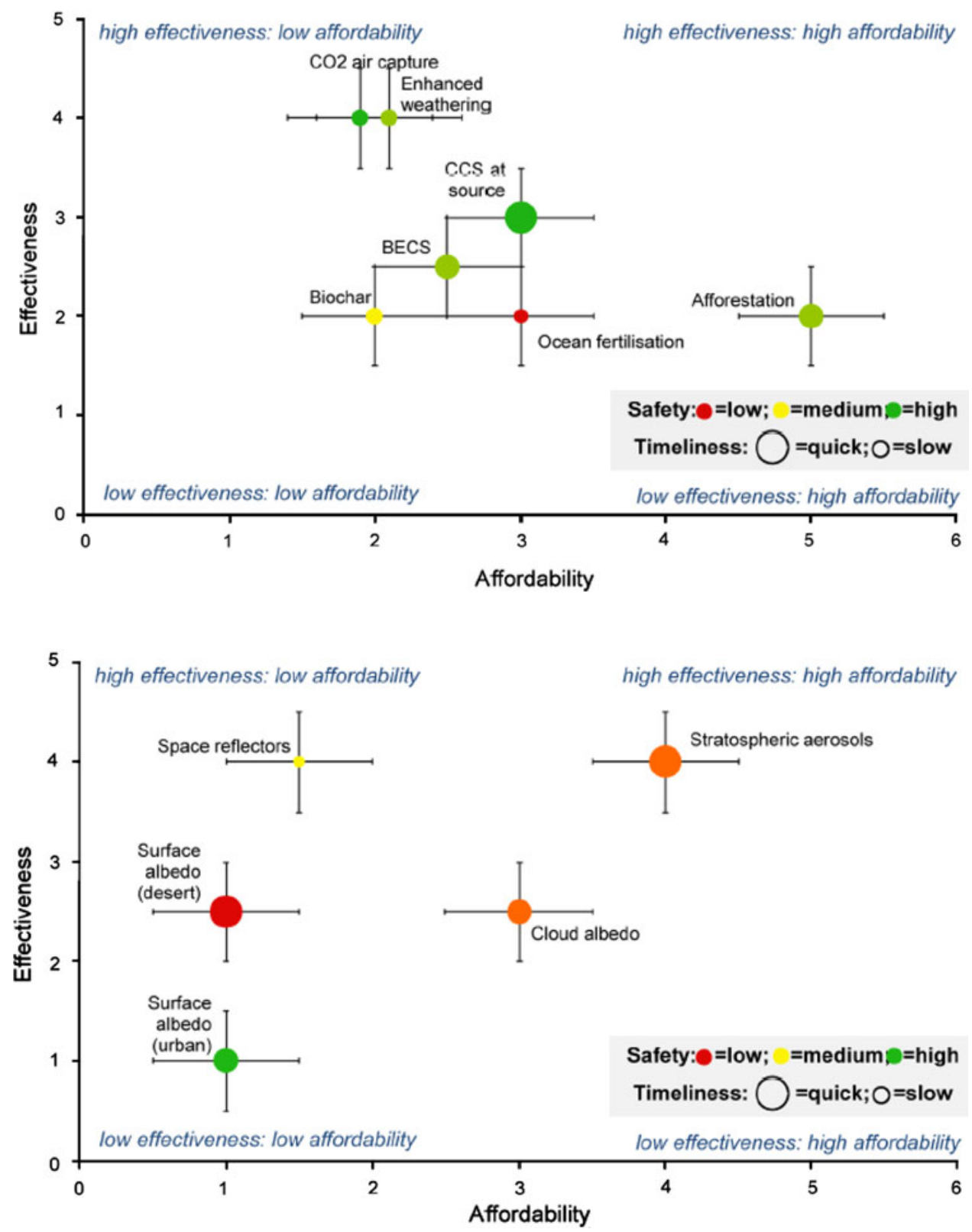

Figure 3 describes a number of $\mathrm{CO}_{2}$ removal techniques, their effectiveness weighted against affordability. $\mathrm{CO}_{2}$ can be removed from the atmosphere through biological, chemical or physical processes. For instance, biological processes are generally very slow and ineffective, but very affordable, whilst direct capture methods (CCS) may be fast but have a low affordability and require safe $\mathrm{CO}_{2}$ storage. One may note that $\mathrm{CCS}$ at the source (e.g. power plant) is the quickest way of removing $\mathrm{CO}_{2}$.

Figure 4 describes solar management techniques, their effectiveness plotted against affordability. Space reflectors, e.g. space-based sunshades that reduce the net solar irradiation of the Earth, represent the most expensive and least effective way of managing the solar input, whilst injection of stratospheric aerosols is a relatively affordable yet effective way of blocking sunlight. Nature provides this management method from time to time through volcanic eruptions. For instance, the recent Mt Pinatubo eruption in 1991 was responsible for a global cooling that lasted some 5 years after the eruption.

The key recommendations regarding climate change and the possibility to implement geoengineering can be summarized as:

- Cutting greenhouse gas emissions is still the key to reduce climate risk and damage

- Geoengineering does not change this. 
- However, we cannot afford to ignore other options that may have the potential to reduce climate risk and damage

- Many geoengineering options are very likely to be technically possible, although there are major uncertainties and potential risks

- Need more research, more public engagement and development of a system of regulation

- Before considering implementation on our climate system!

\section{THE STATUS OF CLIMATE CHANGE RESEARCH}

Professor Lennart Bengtsson pointed out that the increase of greenhouse gases in the atmosphere is accelerating. Since the beginning of industrialization the increase has been c. $40 \%$. As a consequence the radiation balance of the earth is slowly changing. This is due to the fact that $\mathrm{CO}_{2}$ and the other greenhouse gases absorb the heat radiation from the Earth towards space.

The temperature of the Earth has increased by $0.7^{\circ} \mathrm{C}$ since 1900. Melting of arctic sea ice, glacier melting and episodes of extreme heat are indications of a climate transition. However, the warming is irregular and there are large regional differences. Several issues complicate the picture. First, the water vapour follows temperature because the warmer it is the more water can exist in the atmosphere without condensation. Water vapour is also a greenhouse gas and can amplify the original warming up to 2-3 times. The residence time of water vapour in the atmosphere is about a week, although it is continuously replenished through evaporation whilst $\mathrm{CO}_{2}$ will influence the radiation balance for centuries and longer.

Secondly, there is the problem of clouds. Clouds are actually cooling the planet, in fact by six times more than a doubling of the $\mathrm{CO}_{2}$. This is not a simple relationship, because low clouds are cooling and high clouds generally warming. Similar to clouds we have a number of man-made aerosols. The total contribution from those is to offset a part of the warming, but the problem is that we have so far not been able to estimate this as accurately as we wish. This is one of the main causes of the lack of accuracy in climate predictions. A final complicating factor is the complexity of the climate system. Adverse weather conditions can happen by chance, and shorter climate variations can take place without any obvious external effect. Scientists are now more or less in agreement that the warming in the 1930s and 1940 s, as well as the cooling in the 1960s and 1970s, was mainly caused by internal variations of the climate system.

A continued long-term warming of the Earth's climate seems unavoidable and, all efforts should be made to reduce the risks of large changes. The most severe consequences are linked to sea-level rise and changes in precipitation. The sealevel rise is a long-term effect. The speed of change during this century is difficult to determine precisely. The risk for large changes (around $1 \mathrm{~m}$ ) is probably small, but cannot be excluded as it could occur at a later stage. Reduced precipitation in mid-latitudes is potentially a very severe problem since it can create problems in important food-producing areas. In addition, flooding in parts of the tropics and in high latitudes may become an increasingly worrying problem.

More scientific efforts are needed to better determine the risk of serious sea-level rise as well as long-term drought problems.

\section{CONCLUDING REMARKS}

The Earth's climate is characterized by change. Throughout Earth's history the climate has varied between warm and cold. During the last million years the climate cycles have varied between glacial $(\approx 90 \%)$ and interglacial periods, each cycle having a length of about 100,000 years. In comparison with the lifespan of a human being, "natural" changes in the climate are very slow. In the history of advanced human societies $(<5,000$ years), changes have been somewhat larger, to the extent that they may have had a dramatic impact on societies. Historical records show that human society has experienced, suffered, but also managed to adapt to climate change. However, with a growing world population, increasing land-use, and increasing vulnerability to changes in climate, climate change has become an issue of general concern. The issue is in short, if human activity has a negative influence on the global climate, then humans have a responsibility to mitigate the problem.

The cause of today's climate change is a matter of scientific debate. Is the twentieth century warming trend due to Anthropogenic Global Warming (AGW) or an effect of "natural" climate variability? Needless to say, modern human society has made an imprint on the whole of the Earth's environment, has influenced the global ecosystem, and is combusting fossil fuels on a massive scale-thus, in the latter case, increasing the amount of greenhouse gases $\left(\mathrm{CO}_{2}\right)$ to the atmosphere.

The focus of this seminar session was on increasing $\mathrm{CO}_{2}$ levels in the Earth's atmosphere, and methods to mitigate the "problem". However, as noted by Professor Olah, $\mathrm{CO}_{2}$ is also the gas of life without which there would be no advanced life on Earth (it is the basis for photosynthesis). According to Professor Olah humans will need a renewable carbon source, rather than means to capture and store it in an inaccessible form (e.g. carbonates). Furthermore, carbonate capturing processes are slow. A renewable method 
promoted by Professor Olah was to store carbon in a useful form such as methane (methane economy). Prof Lackner noted that the present situation is not sustainable; too much $\mathrm{CO}_{2}$ is being released and this calls for immediate action. The carbonating method has been developed and is now at a stage where it is ready for large-scale use and represents a benign way of storing carbon. This method is used by nature itself (e.g. in limestone). Another, faster, mitigation method, geoengineering, presented by Professor Cox may be open to criticism as being too risky, if not too expensive. It was also noted that a continuation of $\mathrm{CO}_{2}$ emissions is not safe either. However, volcanic activities on Earth point to safe methods for the temporary mitigation of temperature increases. Finally, Professor Bengtsson pointed to the most obvious way to mitigate, i.e. to economize on energy use, in particular the use of fossil energy sources. Other energy sources, including nuclear, must be part of the agenda for the future.

This seminar session was a demonstration of what science and technology can do to alleviate a problem, changing a gloomy perspective into a positive prospect for the future of mankind. The speakers offered a menu of techniques that are already available for the mitigation of anthropogenic influences on climate change. These techniques can be applied at the source (carbon combustion) as well as on a global scale (atmosphere). However, as frequently noted by scientists, research in mitigation methods must be enhanced. Today, there are no signs of a decrease in coal combustion. On the contrary, the trend is towards an increasing use of coal as source of energy.

\section{AUTHOR BIOGRAPHIES}

Kerstin Nibleus $(\square)$ has been Director General at the EU Council of Ministers in Brussels with responsibilities for Environmental Protection and Universities (1995-2008). She has also been Director General of the Swedish Chemicals Inspectorate (1986-1995) and State Secretary for Research Policy. She is a member of several scientific academies in Sweden. She is currently president of the Stockholm Environment Institute.

Address: Energy Committee of the Royal Swedish Academy of Sciences, Stockholm, Sweden.

e-mail: kerstinniblaeus@hotmail.com

Rickard Lundin Professional position: 2003-present Professor at IRF; 1994-2003-Director of the Swedish Institute of Space Physics (IRF); 1988-1994-Professor in Space Physics and assistant director of IRF; 1977-1988-Staff scientist at IRF.

Professional interest: My main research interest is to study how solar radiation and the solar wind interacts with, and affects the environment of the Terrestrial planets, Earth, Mars and Venus. Of particular importance is to understand how the variable solar radiation and solar wind affect planets, from an hourly scale, to the planetary evolution scale (billion year).

Relevant Experience: Principal Investigator (PI) for 9, and coinvestigator in 7 space plasma instruments on space probes launched by ESA, ISAS (Japan) Russia, and Sweden. The space probes have been orbiting the Earth and Mars, one of them (Rosetta) heading towards a comet. Member of the Royal Swedish Academy of Science (KVA) since 1990; Member of the International Academy of Astronautics (IAA), since 1993; Member of a number of international and national societies (e.g. AGU, EGU); Author/coauthor of some 315 publications in international peer-reviewed journals.

Address: Energy Committee of the Royal Swedish Academy of Sciences, Stockholm, Sweden.

Address: Swedish Institute of Space Physics, IRF, Teknikhuset, 90187

Umeå, Sweden.

e-mail: rickard@irf.se 